\title{
Evolving, Not Extinct: Music Reference in the 21st Century
}

\author{
By Donna M. Arnold
}

\section{The Reference Librarian, vol. 56:2, 146-150. Published online by Taylor \& Francis, April 7, 2015}

Not long ago, it would have been unthinkable that academic reference collections and academic reference librarianship would one day be in such a state of upheaval that their very existence is threatened. However, this is just what is happening now because of the computer revolution and its transformative effect on every component of the library profession. As the Internet increasingly dominates contemporary life, many people, even academics, conclude that "everything is online" and thus, anyone can find all available resources or answer any questions with easy Google searches. This strongly suggests that tangible collections and inperson reference librarians are totally obsolete. From my perspective as the long-time music reference librarian in a large academic music research library, I strongly disagree.

During my career, I have navigated monumental change. For many years, my library resources consisted of tangible materials: print books, print scores, print journals, LPs, and card catalogs. As the computer revolution enriched our profession, online catalogs, CDs, the Internet, and various Web-based subscription products gradually reached the Music Library. Our card catalogs are now gone, but our other traditional and digital resources remain, and I use all forms of both kinds in my reference work.

In common with scholars from other branches of the humanities, music scholars care deeply about the latest research and resources, but they also care deeply about research and resources from the past. Thus, our music library's current environment is particularly advantageous, for it allows our patrons to access the full range of our traditional and electronic collections. Our students benefit from working with well-informed faculty members and librarians who want them to know and use the best resources of all types, not just those that are a few clicks away. For music research, the best resources are sometimes electronic, sometimes traditional, but usually both.

Over the years, music librarians have often pointed out that music library patrons have special needs that set them apart from other library patrons (Cristensen, Du Mont, \& Green, 2001; Dougan, 2013). This is mainly because music libraries contain music scores and sound recordings in addition to the books and journals common to other fields, and these special formats pose their own peculiar problems. It is also because classical music is at the core of most academic music programs. Classical music studies often involve musical works and scholarly writings in languages other than English, especially German, French, and Italian. Although I cannot take the time to do lengthy translations for patrons, my having studied those languages is frequently useful to them. 
Some day every aspect of music and music librarianship may become computerized, but such a day is still in the distant future. Most performing musicians play acoustic instruments rather than electronic ones, and for many reasons, most are very satisfied with the tangible print scores they use. The definitive digital score-reading device does not yet exist, but whenever it does arrive, it is unlikely to supplant print scores for a long time. Our patrons still depend heavily on our print score collections for both performance and research. Although we now acquire e-books, to date they represent only a small percentage of our holdings, so our patrons also depend heavily on our much larger collection of print books. This is appropriate, for in our field, significant music books typically remain relevant for decades. Of course our patrons listen to music from YouTube and online vendors, but they also listen to sound recordings in all the formats we offer: streaming audio databases, CDs, LPs, and occasionally even historical formats such as 78s and cylinders. Our CD circulation statistics continue to be robust. Moreover, a number of connoisseurs are finding the sound quality of long-playing vinyl records preferable to that of any other medium (Justice, 2013).

Recently, our main library stopped having a print reference section and the books were all moved to the open shelves or to remote storage. For some fields, this move was appropriate, for patrons were no longer using those reference books. In contrast, however, the music library's reference section is still very much intact, and in response to faculty directives, our students make good use of it.

Our Music Library's reference collection contains types of resources unique to music, and it is highly unlikely that they will all be digitized in the near future. For example, there are large numbers of thematic catalogs that present incipits of musical scores and vitally important primary-source information about individual composers' works. There are also large numbers of discographies, many very specialized, that cite thousands of sound recordings of historical significance.

Soon all such resources will likely be born digital, and then be available for lease. However, we have good cause for worry about how many of them we will be able to afford and maintain. As we know from current experience, budget constraints routinely force libraries to cancel electronic subscriptions. Such constraints cannot, however, deprive libraries of the tangible items they already own. Given that our library's collection development policy favors electronic formats, it may be an uphill battle for us in the Music Library, but there is a compelling argument for our continuing to buy tangible materials.

Identifying and accessing scholarly articles has always been a main component of academic research. Thanks to services such as JStor, complete runs of our discipline's core titles have been digitized. We provide access to those and many other electronic journals, but we also provide a vast collection of print journals that are unavailable or only partially available online. Subject-specific subscription databases such as RILM and Music Index link to full text of thousands of articles, but only provide abstracts of, or citations for, thousands of articles in print-only journals and books of essays. Because of copyright constraints, Google Scholar can only cite or provide short excerpts from most such articles. It is a great strength of our library that we still have many of those print sources, and I frequently help patrons access them. 
Our print and digital music collections combine with findings from skilled Internet searching to provide a formidable reference arsenal that was unimaginable before the computer age.

Electronic resources have not replaced our print collections, but rather have greatly enhanced them. However, using either effectively requires certain skills. Both students and faculty need to learn these skills to get the most from our resources, and the reference librarians who use them regularly are the ideal people to teach them.

Students are not the only ones who do not understand that there is a great difference between searching Google for personal interest and searching Google, library catalogs, or scholarly databases for academic purposes. I help many patrons, faculty included, whose Google, catalog, or database searches fall far short of answering their research questions. What would happen to such patrons in libraries without reference services? I agree with a well-known music reference librarian who said years ago that computerization has resulted in more, not fewer, reference questions (Lasocki, 2000).

As our culture becomes increasingly computerized and dehumanized, higher education is following the trend. Courses in many disciplines, music included, are now totally online. The expectation that libraries will also be totally online naturally follows. As it should, this prospect is causing serious concern in our field. For example, there was a May 2014 thread on AMS-L, the American Musicological Society's listserv, as to whether a university could now support a doctoral or master's program in music with an online-only library. In the lively discussion of this topic, the consensus was no. I agree, for far too many essential components of a music research library are not currently online.

It is crucial for scholars to embrace the latest technologies and gain all possible benefit from them. However, if researchers in our field ignore our content-rich tangible collections and deal only with what they can easily access on their electronic devices, they are in dangerous territory. Opting for convenience rather than seeking out the best, most relevant sources precludes doing serious, thorough, research.

Patrons ask me questions by various means: in person, by phone, and online. In all cases, I have the luxury of using the best available resources in all formats to find answers, and I do whatever it takes to get results. While serving undergraduates and community members who usually have basic questions, we also routinely serve master's students, doctoral students, faculty scholars, and independent scholars who need in-depth assistance with projects such as theses, dissertations, and pending publications. In working with such patrons, I might use print resources as diverse as a narrowly focused bibliography or discography, a polyglot dictionary of musical terms, a 19th-century journal, a recent European music encyclopedia, or a rare book or score from our special collections, as well as electronic resources such as Web sites from distant research libraries, subscription article databases, sheet music vendors' online catalogs, or non-English versions of Google. In addition, I might consult colleagues who have specialized knowledge.

Our tangible resources, electronic resources, and human resources are all vitally important to my music reference work. I now cannot fathom having to get along without our electronic 
resources, but neither can I fathom having to do without our vast tangible collections and my colleagues' expertise. Having all of these is, to me, the best of all possible worlds.

I am no seer, but based on my experience to date, I predict that music research and music reference work will long continue to flourish as a rich combination of traditional resources, electronic resources, and human expertise. As pressure mounts to computerize and depersonalize, we must be especially proactive in order to retain this balance. We must keep library administrators apprised of the needs that set our field apart from others. We also must continue to foster the close relationship we have with our faculty, for it is vital that faculty members continue to appreciate and support what we have to offer. No matter how we librarians view the situation, we are, in fact, only as relevant to the students as their teachers think we are.

Clearly, computer technology continues to alter our profession with lightning speed. While I constantly celebrate all of its remarkable benefits, I also entertain serious fears. One is that, in our shortsighted, throwaway culture, the latest high-tech fads will increasingly dominate academic libraries, while tangible collections of inestimable worth will continue to be unwisely destroyed (Baker, 2001). Another is that, as more and more resources are prepackaged en masse by profit-motivated vendors, subject specialists will eventually be eliminated from the library profession. For many fields in which reference librarians currently have very little contact with their constituencies, the groundwork is already in place. I cannot believe that music is the only field for which such changes would constitute a tragic mistake.

\section{REFERENCES}

1. Baker, N. (2001). Double fold: Libraries and the assault on paper. New York, NY: Random House.

2. Christensen, B., Du Mont, M., \& Green, A. (2001). Taking note: Assessing the performance of reference service in academic music libraries: A progress report. Notes, 58, 39-54.

3. Dougan, K. (2013). Delivering and assessing music reference services. The Reference Librarian, 54, 38-54.

4. Justice, A. (2013, March). Do they (or we) know it's clipping?: Sound gold quality and the music librarian's role in educating younger listeners. Paper presented at the Music Library Association Annual Conference, San Jose, CA.

5. Lasocki, D. (2000). Reference. Notes, 56, 605-610. 